\title{
2018 CIPHI Awards
}

The 2018 CIPHI Awards were handed out during the most recent National AGM in November in Saskatoon, Saskatchewan. Congratulations to all the winners!

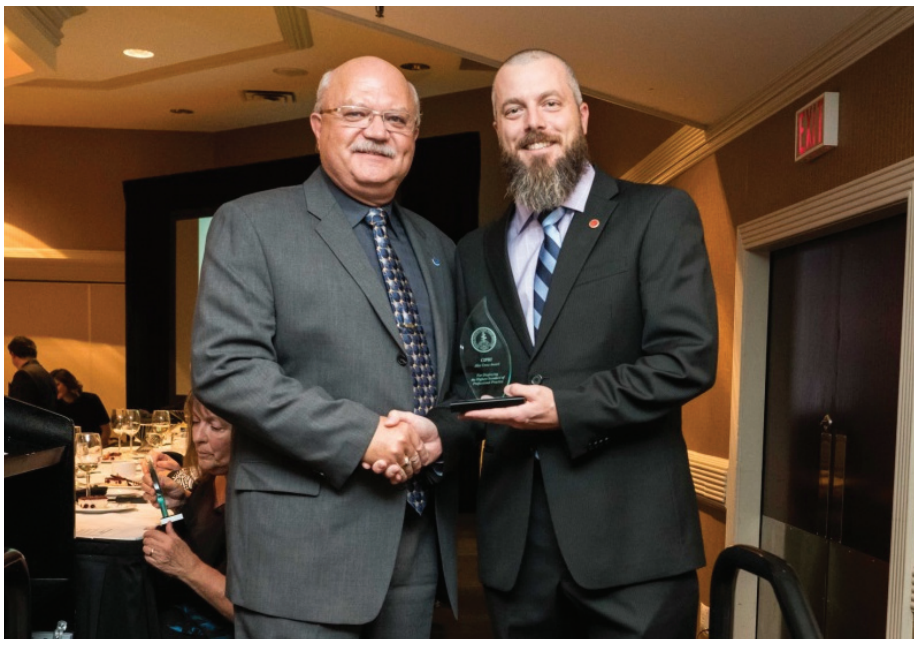

Russell Scott from Saskatchewan accepting the Alex Cross award. Presented by Kevin Kapell (SK Branch President).

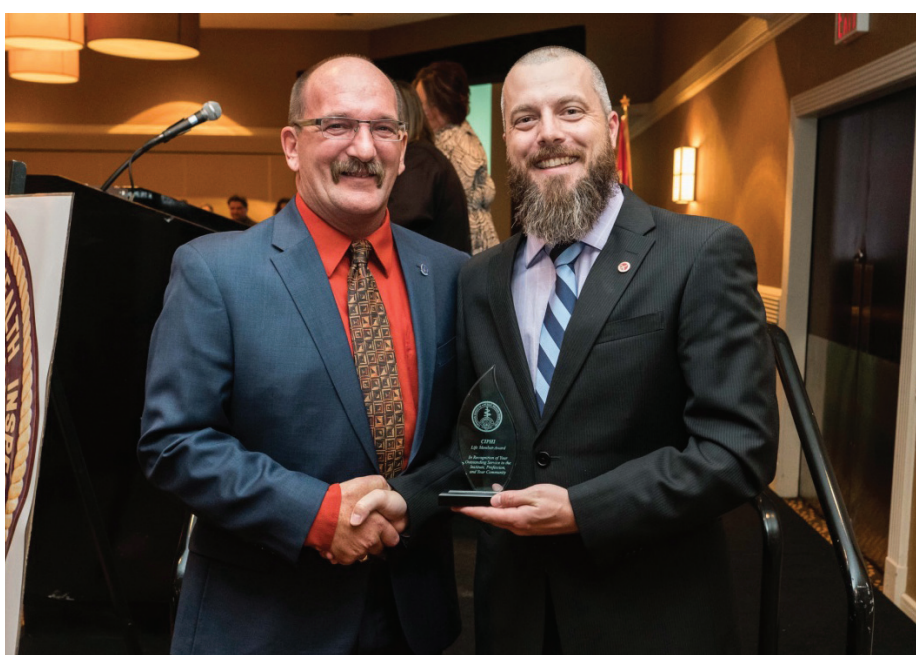

Kevin Kapell (SK Branch President) presents the Life Membership Award. Accepting is Ken Cross from Saskatchewan.

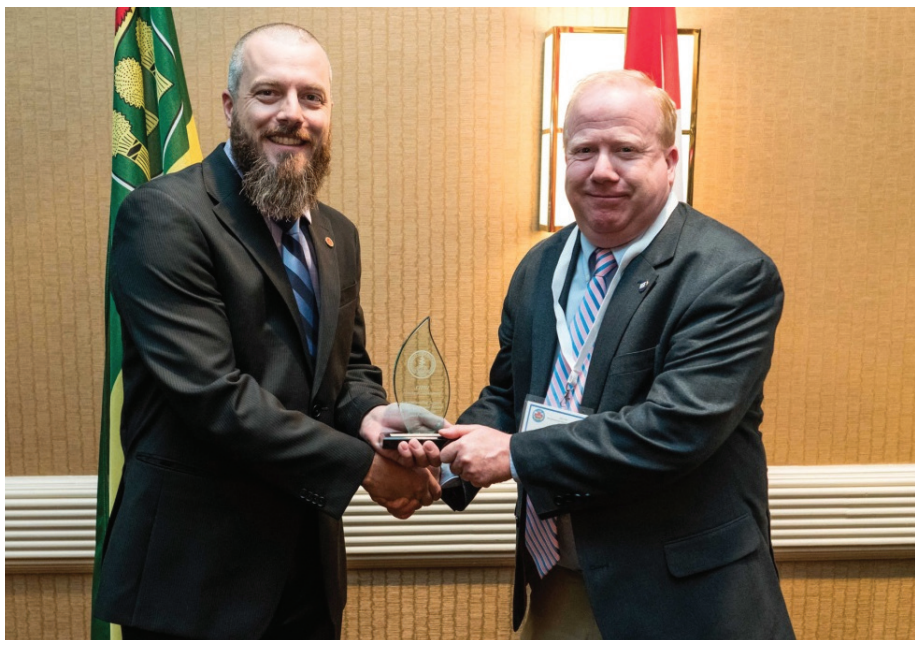

Kevin Kapell (SK Branch President) presents the Honorary Membership Award to Harold Chase accepting on behalf of Stan Hazen, NSF International.

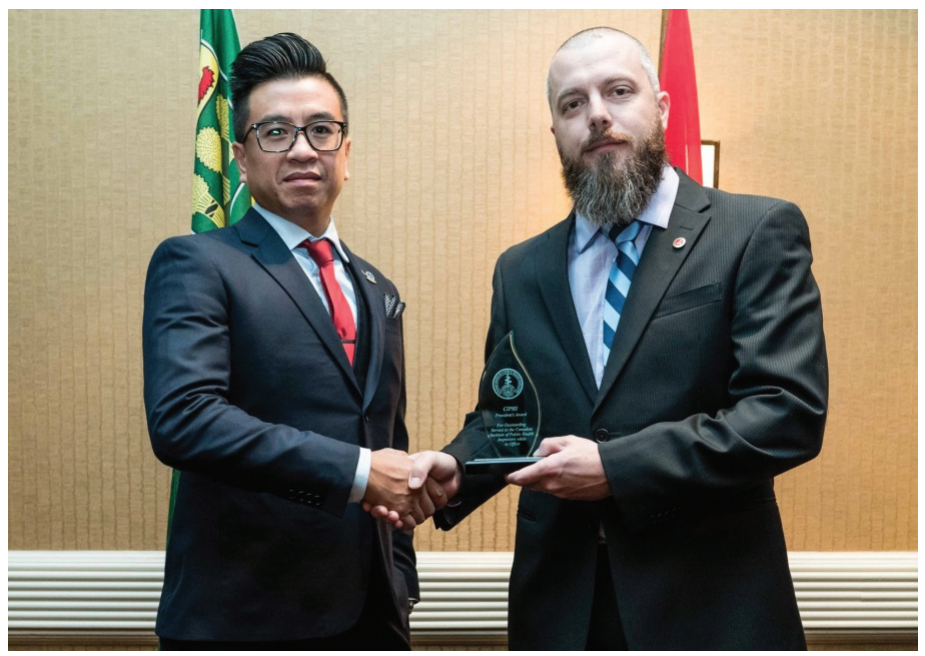

Kevin Kapell (SK Branch President) presents the President's Award to Tony Thepsouvanh accepting on behalf of Garth Gosselin of Alberta. 